\title{
Model intercomparison of indirect aerosol effects
}

\author{
J. E. Penner ${ }^{1}$, J. Quaas ${ }^{2, *}$, T. Storelvmo ${ }^{3}$, T. Takemura ${ }^{4}$, O. Boucher ${ }^{5,{ }^{* *}}$, H. Guo ${ }^{1}$, A. Kirkevåg ${ }^{3}$, J. E. Kristjánsson ${ }^{3}$, \\ and Ø. Seland ${ }^{3}$ \\ ${ }^{1}$ University of Michigan, Department of Atmospheric, Oceanic and Space Sciences, Ann Arbor, USA \\ ${ }^{2}$ Laboratoire de Météorologie Dynamique, CNRS/Institut Pierre Simon Laplace, 4, place Jussieu, 75005 Paris, France \\ ${ }^{3}$ University of Oslo, Department of Geosciences, Oslo, Norway \\ ${ }^{4}$ Research Institute for Applied Mechanics, Kyushu University, Fukuoka, Japan \\ ${ }^{5}$ Laboratoire d'Optique Atmosphérique, CNRS/Universite de Lille I, 59655 Villeneuve d'Ascq Cedex, France \\ *now at: Max Planck Institute for Meteorology, Bundesstraße 53, Hamburg, Germany \\ ** now at: Hadley Centre, Met Office, FitzRoy Road, Exeter EX1 3PB, UK
}

Received: 21 November 2005 - Published in Atmos. Chem. Phys. Discuss.: 28 February 2006

Revised: 23 June 2006 - Accepted: 27 June 2006 - Published: 21 August 2006

\begin{abstract}
Modeled differences in predicted effects are increasingly used to help quantify the uncertainty of these effects. Here, we examine modeled differences in the aerosol indirect effect in a series of experiments that help to quantify how and why model-predicted aerosol indirect forcing varies between models. The experiments start with an experiment in which aerosol concentrations, the parameterization of droplet concentrations and the autoconversion scheme are all specified and end with an experiment that examines the predicted aerosol indirect forcing when only aerosol sources are specified. Although there are large differences in the predicted liquid water path among the models, the predicted aerosol first indirect effect for the first experiment is rather similar, about $-0.6 \mathrm{Wm}^{-2}$ to $-0.7 \mathrm{Wm}^{-2}$. Changes to the autoconversion scheme can lead to large changes in the liquid water path of the models and to the response of the liquid water path to changes in aerosols. Adding an autoconversion scheme that depends on the droplet concentration caused a larger (negative) change in net outgoing shortwave radiation compared to the 1st indirect effect, and the increase varied from only $22 \%$ to more than a factor of three. The change in net shortwave forcing in the models due to varying the autoconversion scheme depends on the liquid water content of the clouds as well as their predicted droplet concentrations, and both increases and decreases in the net shortwave forcing can occur when autoconversion schemes are changed. The parameterization of cloud fraction within models is not sensitive to the aerosol concentration, and, therefore, the response of the modeled cloud fraction within the present models appears to be smaller than that which would be associated
\end{abstract}

Correspondence to: J. E. Penner

(penner@umich.edu) with model "noise". The prediction of aerosol concentrations, given a fixed set of sources, leads to some of the largest differences in the predicted aerosol indirect radiative forcing among the models, with values of cloud forcing ranging from $-0.3 \mathrm{Wm}^{-2}$ to $-1.4 \mathrm{Wm}^{-2}$. Thus, this aspect of modeling requires significant improvement in order to improve the prediction of aerosol indirect effects.

\section{Introduction}

Tropospheric aerosols are important in determining cloud properties, but it has been difficult to quantify their effect because they have a relatively short lifetime and so vary strongly in space and time. The direct radiative effect of aerosols (i.e., the extinction of sunlight by aerosol scattering and absorption) can cause changes to clouds through changes in the temperature structure of the atmosphere (termed the semi-direct effect of aerosols on clouds). This effect will tend to decrease clouds in the layers where aerosol absorption is strong, but may increase clouds below these levels (Ackerman et al., 1989; Hansen et al., 1997; Penner et al., 2003; Feingold et al., 2005). In addition, aerosols may alter clouds by acting as cloud condensation nuclei (CCN). Two modes of aerosol indirect effects (AIE) may be distinguished. First, an increase of aerosol particles may increase the initial cloud droplet number concentration (CDNC) if the cloud liquid water content is assumed constant. This effect, termed the first indirect effect, tends to cool the climate because it increases the cloud optical depth by approximately the $1 / 3$ power of the change in the cloud droplet number (Twomey, 1974). An increase in the cloud optical depth increases cloud

Published by Copernicus GmbH on behalf of the European Geosciences Union. 
albedo and thus reflectivity, with clouds of intermediate optical depth being the most susceptible. The second indirect effect relates to changes in cloud morphology associated with changes in the precipitation efficiency of the cloud. An increase in the cloud droplet number concentration will decrease the size of the cloud droplets. Since the cloud microphysical processes that form precipitation depend on the size of the droplets, the cloud lifetime as well as the liquid water content, the height of the cloud, and the cloud cover may increase, though the response of the cloud to changes in the droplet number concentration is sensitive to the local meteorological conditions (Ackerman et al., 2004). For low, warm clouds, these changes will tend to add an additional net cooling to the climate system. Both satellite and in-situ observations have been used to determine the first indirect effect (Nakajima et al., 2001; Bréon et al., 2002; Feingold et al., 2003; Penner et al., 2004; Kaufmann et al., 2005). But it has been difficult to determine the 2nd indirect effect, because changes in the observed liquid water path, cloud height and cloud cover are influenced by large-scale and cloud-scale dynamics and thermodynamics as well as by the influence of aerosols on cloud microphysics. General circulation model (GCMs) include the treatment of a variety of dynamical and physical processes and are therefore able to simulate interactions between many climate parameters. Nevertheless, their quantification of the aerosol indirect effect is suspect because the scale of a GCM grid box is too coarse to properly resolve cloud dynamics and microphysics. Comparing the results of different models and simulations can help us determine the uncertainty associated with global model estimates of the aerosol indirect effect.

Previously, Boucher and Lohmann (1995) compared two GCMs to examine the differences in predictions of the first indirect effect associated with sulfate aerosols, and Chen and Penner (2005) have examined a set of simulations using different model formulations to understand how different choices of parameterization impact the magnitude of the first indirect effect. Here, we perform six different model experiments with three different GCMs to determine the differences between models for the first indirect effect as well as differences in the combined first and second indirect effects. Section 2 describes the prescribed experiments while Sect. 3 provides an overview of the main results together with a discussion. Section 4 gives our conclusions.

\section{Description}

The three models examined here are the Laboratoire de Météorologie Dynamique-Zoom (LMD-Z) general circulation model (Li, 1999), the Center for Climate System Research (CCSR)/University of Tokyo, National Institute for Environmental Studies (NIES), and Frontier Research Center for Global Change (FRCGC) (hereafter CCSR) general circulation model (Numaguti et al., 1995; Hasumi and
Emori, 2004), and the version of the National Center for Atmospheric Research (NCAR) Community Atmosphere Model version 2.0.1 (CAM-2.0.1) (http://www.ccsm.ucar. edu/models/) modified at the University of Oslo (Kristjansson, 2002; Storelvmo et al., 2006). Below we briefly describe each model's cloud fraction and condensation schemes. The model schemes for determining cloud droplet number are described below in the Sect. 2.2.

\subsection{Cloud schemes in the models}

In the LMD-Z model, an assumed subgrid scale probability distribution of total water is used to determine cloud fraction. This distribution is uniform and extends from $q_{t}-\Delta q_{t}$ to $q_{t}+\Delta q_{t}$ where $q_{t}$ is the total (liquid, ice and vapor) water in the grid and $\Delta q_{t}=r q_{t}$ with $0<r<1$ varying in the vertical. The portion above saturation determines the cloud fraction of the grid (Le Treut and Li, 1991). The removal of cloud water mixing ratio follows a formula that is similar to that developed by Chen and Cotton (1987) but ignores their term that involves spatial inhomogeneities in liquid water:

$$
P=-\frac{d q_{l}}{d t}=c^{\prime} \rho_{a}^{11 / 3} q_{l}^{7 / 3} N_{d}^{-1 / 3} H\left(c^{\prime \prime} \rho_{a}^{2 / 3} q_{l}^{1 / 3} N_{d}^{-1 / 3}-r_{0}\right)
$$

where

$c^{\prime}=1.1\left(\frac{3}{4}\right)^{4 / 3} \pi^{-1 / 3} \rho_{w}^{-4 / 3} c k$

and

$c^{\prime \prime}=1.1\left(\frac{3}{4}\right)^{1 / 3} \pi^{-1 / 3} \rho_{w}^{-1 / 3}$,

$q_{l}$ is the in-cloud liquid water mixing ratio, $\rho_{a}$ is the air density, $\rho_{w}$ is the density of water, $H$ is the Heaviside function, $N_{d}$ is cloud droplet number, and $k=1.19 \times 10^{8} \mathrm{~m}^{-1} \mathrm{~s}^{-1}$ is a parameter in the droplet fall velocity. In the experiments described here, the threshold value for $r_{0}$ was set to $8 \mu \mathrm{m}$, and the parameter $c$ was set to 1 . Other aspects of the cloud microphysical scheme are described in Boucher et al. (1995). Note that for the simulations reported here, collection of cloud drops by falling rain was not included. Moreover, the LMD-Z model did not include a prognostic equation for droplet number concentration. This was simply diagnosed based on the aerosol fields.

Convective condensation in the LMD-Z model follows the Tiedke et al. (1989) scheme for convection. Complete detrainment of the convective cloud water is assumed at each physics time step. Thus the convective cloud water is immediately assumed to become stratiform for the purpose of determining the subgrid probability distribution of liquid water. The horizontal resolution of the LMD-Z model was approximately $3.75^{\circ}$ longitude by $2.5^{\circ}$ latitude with 19 vertical layers with centroids varying from $1004.26 \mathrm{hPa}$ to $3.88 \mathrm{hPa}$.

The CCSR model determines cloud fraction based on Le Treut and Li (1991). This is similar to the method used in 
Table 1. Description of model experiments and purpose.

\begin{tabular}{|c|c|c|c|c|c|c|}
\hline experiment & 1 & 2 & 3 & 4 & 5 & 6 \\
\hline $\begin{array}{l}\text { Purpose: to examine influence of: } \\
\text { Aerosol distributions }\end{array}$ & $\begin{array}{l}\text { Cloud variability } \\
\text { prescribed }\end{array}$ & $\begin{array}{l}\text { CDNC parameterization } \\
\text { prescribed }\end{array}$ & $\begin{array}{l}\text { Cloud lifetime effect } \\
\text { prescribed }\end{array}$ & $\begin{array}{l}\text { Autoconversion scheme } \\
\text { prescribed }\end{array}$ & Aerosol distribution & Direct effect \\
\hline CDNC parameterization & BL95 "A" & model's own & model's own & model's own & model's own & model's own \\
\hline Autoconversion parameterization & S78 & S78 & KK00 & model's own & model's own & model's own \\
\hline Direct radiative effect of aerosols & no & no & no & no & no & yes \\
\hline
\end{tabular}

BL95: Boucher and Lohmann (1995)

S78: Sundquist (1978)

KK00: Khairoutdinov and Kogan (2000)

Prescribed aerosol distributions are as in Chen and Penner (2005)

Interactive aerosols are computed using the AEROCOM emissions (http://nansen.ipsl.jussieu.fr/AEROCOM)

the LMD-Z model. In particular, the liquid content, $l$, is determined as follows,

$l=\left\{\begin{array}{cc}0 & (1+b) q_{t} \leq q^{*} \\ \frac{\left[(1+b) q_{t}-q^{*}\right]^{2}}{4 b q_{t}} & (1-b) q_{t}<q^{*}<(1+b) q_{t} \\ q_{t}-q^{*} & (1-b) q_{t} \geq q^{*}\end{array}\right.$

where $q^{*}$ is the saturated mixing ratio and $b$ varies between 0 and 1 , depending on the mixing length and cloud base mass flux. The ratio of liquid cloud water to total cloud water $f_{\text {liq }}$ is given by

$f_{\text {liq }}=\min \left[\max \left(\frac{T-T_{w}}{T_{s}-T_{w}}, 0\right), 1\right]$

where $T$ is temperature, and $T_{s}$ and $T_{w}$ are set to $273.15 \mathrm{~K}$ and $258.15 \mathrm{~K}$, respectively. The rate of formation of precipitation was determined using a scheme developed by Berry (1967):

$P=\frac{\alpha \rho_{a} q_{l}}{\beta+\gamma \frac{N_{d}}{\rho q_{l}}}$

The parameters in this scheme were set to $\alpha=0.01, \beta=0.12$ and $\gamma=1 \times 10^{-12}$. The model includes a representation for autoconversion, accretion, evaporation, freezing, and melting of ice. The accretion term is $F_{p} \times$ acc where $F_{p}$ is the precipitation flux above the applied layer and acc $=1$, which is simplified from the collision equation between cloud and rain droplets. The cumulus parameterization scheme is base on Arakawa and Schubert (1974). Further details, including the prognostic treatment for droplet number, are given in Takemura et al. (2005). The model was run a horizontal resolution of $1.125^{\circ}$ longitude by $1.121^{\circ}$ latitude and had 20 vertical layers with centroids from $980.08 \mathrm{hPa}$ to $8.17 \mathrm{hPa}$.

In the Oslo version of CAM, cloud water, condensation and microphysics follows the scheme developed by Rasch and Kristjansson (1998). The stratiform cloud fraction is diagnosed from the relative humidity, vertical motion, static stability and convective properties (Slingo, 1987), except that an empirical formula that relates cloud fraction to the difference in the potential temperature between $700 \mathrm{hPa}$ and the surface found by Klein and Hartmann (1993) is used for cloud fraction over oceans. Precipitation formation by liquid cloud water is calculated using the formulation of Chen and Cotton (1987) with modifications by Liou and Ou (1989) and Boucher et al. (1995):

$P=C_{l, a u t} q_{l}^{2} \rho_{a} / \rho_{w}\left(q_{l} \rho_{a} / \rho_{w} N_{d}\right)^{1 / 3} H\left(r_{31}-r_{31 c}\right)$

where $C_{l, a u t}$ is a constant and was set to $5 \mathrm{~mm} /$ day, $r_{31}$ is the mean volume droplet radius and $r_{31 c}$ is a critical value which was set to $15 \mu \mathrm{m}$. The droplet radius was determined from the liquid water content of the cloud and the predicted droplet number concentration. Since the CAM-Oslo model did not include a prognostic equation for cloud droplets in these experiments (they were simply diagnosed from the aerosol fields as in the LMD-Z model), the calculation of droplet number did not change as a result of coalescence and autoconversion and other collection processes. In addition, the cloud droplet effective radius had a lower limit of $4 \mu \mathrm{m}$ and an upper limit of $20 \mu \mathrm{m}$. Collection of cloud drops by rain and snow were represented as described in Rasch and Kristjansson (1998) but these processes were only included in experiments 4-6. Ice water was also removed by autoconversion of ice to snow, and by collection of ice by snow. Details are given in Rasch and Kristjansson (1998).

Convection in the CAM-Oslo model follows the Zhang and McFarlane (1995) scheme for penetrative convection and the Hack (1994) scheme for shallow convection. The model simulations were run at a horizontal resolution of 2.5 longitude by 2 latitude with 26 vertical layers having centroids from $976.38 \mathrm{hPa}$ to $3.54 \mathrm{hPa}$.

\subsection{Design of the model experiments}

Model estimates of the aerosol indirect effect depend not only on the cloud schemes in the models, but also on the relationship adopted between aerosols and cloud droplets, the effect of the aerosols on precipitation efficiency, and the model representation of aerosols. To distinguish how each of these factors affect the calculated radiative indirect effect, we designed a set of experiments in which these factors are first 
Table 2. Constants used in the parameterization of droplet concentrations for experiment 1 .

\begin{tabular}{lcc}
\hline Cloud type: & A & B \\
\hline Continental stratus & 174 & 0.257 \\
Marine stratus & 115 & 0.48 \\
\hline
\end{tabular}

constrained in each of the models and then relaxed to each model's own representation of the process. Six model experiments each with both present day and pre-industrial aerosol concentrations were specified. These are described next and outlined in Table 1.

For the first experiment (and also experiments 2-4) we prescribed the monthly average aerosol mass concentrations and size distribution and we prescribed the parameterization of cloud droplet number concentration. We also did not allow any effect of the aerosols on precipitation efficiency nor any direct effect of the aerosols. We specified that models use the precipitation efficiency in Sundquist (1978) which depends only on the in-cloud liquid water mixing ratio:

$$
P=10^{-4} q_{l}\left[1-e^{-\left(q_{l} / q_{c}\right)^{2}}\right]
$$

where $q_{l}$ is the in-cloud liquid water mixing ratio $(\mathrm{kg} / \mathrm{kg})$ and $q_{c}=3 \times 10^{-4}$. This experiment (as well as experiments 2-5) does not include aerosol direct effects on the heating profile in the model (thus precluding any effects from the so-called "semi-direct" effect). The standard aerosol model fields were adopted from the "average" IPCC model experiment (e.g. Chen and Penner, 2005), but with a standard exponential fall off with altitude (with a $2 \mathrm{~km}$ scale height) to facilitate interpolation of these aerosol fields to each model grid. The fixed method to relate aerosol concentrations to droplet number concentrations was that developed by Boucher and Lohmann (1995) which only requires the sulfate mass concentrations as input:

$N_{d}=A\left(m_{\mathrm{SO}_{4}^{2-}}\right)^{B}$,

where $m_{\mathrm{SO}_{4}^{2-}}$ is the mass concentration of sulfate aerosol at cloud base in $\mu \mathrm{g} \mathrm{m}^{-3}$, and $A$ and $B$ are empirically determined constants. The values the we adopted for $A$ and $B$ (from formula "A" of Boucher and Lohmann, 1995) are given in Table 2.

In this first experiment, the only factor that should distinguish the different model results is their separate cloud formation and radiation schemes.

The second experiment was set up as in the first, but each modeler used their own method for relating the aerosols to droplets. Since this second experiment also prescribed the aerosol mass concentrations and size distribution, the only issue that would distinguish the model results (other than their separate cloud and radiation schemes) is the method of relating aerosols to cloud droplet number concentration. These schemes are described next.

In the LMD-Z model, the cloud droplet nucleation parameterization was diagnosed from aerosol mass concentration using the empirical formula " $D$ " of Boucher and Lohmann (1995). This method uses the formula given above for experiment 1 , but the constants $A$ and $B$ had the values 162 and 0.41 , respectively.

Both the CAM-Oslo model and the CCSR model used the multi-modal formulation by Abdul-Razzak and Ghan (2000) to calculate droplet concentrations. In this scheme, the droplet concentration, $N_{c}$, originating from an aerosol component $i$ is diagnosed as follows:

$N_{c i}=N_{a i}\left\{1+\left(S_{m i}^{2} \sum_{j=1}^{J} \frac{F_{j}}{S_{m j}^{2}}\right)^{\frac{b\left(\sigma_{a i}\right)}{3}}\right\}^{-1}$

where

$S_{m i}=\frac{2}{\sqrt{B_{i}}}\left(\frac{A}{3 r_{m i}}\right)^{\frac{3}{2}}$

and

$F_{j}=\left\{f_{1}\left(\sigma_{a j}\right)\left(\frac{A N_{a j} \beta}{3 \alpha \omega}\right)^{2}+f_{2}\left(\sigma_{a j}\right) \frac{2 A^{3} N_{a j} \beta \sqrt{G}}{27 B_{j} r_{m j}^{3}(\alpha \omega)^{3 / 2}}\right\}^{3}$.

Here, $j$ also refers to an aerosol component, $J$ is the total number of aerosol components, $N_{a i}$ is the aerosol particle number concentration of component $i, w$ is the updraft velocity, $r_{m i}$ and $\sigma_{a i}$ are the mode radius and standard deviation of the aerosol particle size distribution, respectively, $A$ and $B_{i}$ are the coefficients of the curvature and solute effects, respectively, $a$ and $b$ are functions of the saturated water vapor mixing ratio, temperature, and pressure, $G$ is a function of the water vapor diffusivity, saturated water vapor pressure, and temperature, and $f_{1}, f_{2}$, and $b$ depend on the standard deviation of the aerosol particle size distribution.

For the CCSR model the updraft velocity was calculated from the formulation in Lohmann et al. (1999), while in the CAM-Oslo model the mean updraft velocity was set to the large scale updraft calculated by the GCM and subgrid scale variations followed a Guassian distribution with standard deviation:

$\sigma_{w}=\frac{\sqrt{2 \pi} K}{\Delta z}$

where $K$ is the vertical eddy diffusivity and $\Delta z$ is the model layer thickness (Ghan et al., 1997).

In both experiments 1 and 2, one expects only small changes to the liquid water path, cloud height, and cloud fraction between present day and pre-industrial simulations since the aerosols are not allowed to change the precipitation efficiency. 
Table 3. Difference in present day and pre-industrial outgoing solar radiation.

\begin{tabular}{lcccccc}
\hline & exp. 1 & exp. 2 & exp. 3 & exp. 4 & exp. 5 & exp. 6 \\
\hline Whole-sky & & & & & & \\
CAM-Oslo & -0.648 & -0.726 & -0.833 & -0.580 & -0.365 & -0.518 \\
LMD-Z & -0.682 & -0.597 & -0.722 & -1.194 & -1.479 & -1.553 \\
CCSR & -0.739 & -0.218 & -0.773 & -0.350 & -1.386 & -1.368 \\
Clear-sky & & & & & & \\
CAM-Oslo & -0.063 & -0.066 & -0.026 & 0.014 & -0.054 & -0.575 \\
LMD-Z & -0.054 & 0.019 & 0.030 & -0.066 & -0.126 & -1.034 \\
CCSR & 0.018 & -0.0068 & -0.045 & -0.008 & 0.018 & -1.168 \\
Change in cloud forcing & & & & & & \\
CAM-Oslo & -0.584 & -0.660 & -0.807 & -0.595 & -0.311 & 0.056 \\
LMD-Z & -0.628 & -0.616 & -0.752 & -1.128 & -1.353 & -0.518 \\
CCSR & -0.757 & -0.212 & -0.728 & -0.342 & -1.404 & -0.200 \\
\hline
\end{tabular}

1 Change in cloud forcing is the difference between whole sky and clear sky outgoing radiation in the present day minus pre-industrial simulation. The large differences seen between experiments 5 and 6 are due to the inclusion of the clear sky component of aerosol scattering and absorption (the direct effect) in experiment 6.

The third experiment introduced the effect of aerosols on the precipitation efficiency. For this experiment, the formulation of Khairoutdinov and Kogan (2000) for the rate of conversion of cloud droplets to precipitation was implemented in the models:

$P=1350 q_{l}^{2.47} N_{d}^{-1.79}$.

In the fourth experiment, we continued to prescribe aerosol size and chemical composition, but each modeler used both their own method for relating the aerosols to droplets and their own method for determining the effect of aerosols on the precipitation efficiency. This experiment combines the effect of each model's own determination of the change in cloud droplet number concentration caused by the common aerosols with changes in the precipitation efficiency using each model's parameterization (described above) and changes in each model's thermodynamic and dynamic response of clouds.

Finally, the fifth and sixth experiments used each model's own calculation of aerosol fields, but the emissions of aerosols and aerosol precursor gases were specified as in the AEROCOM B experiment (Dentener et al., 2006). The fifth experiment does not include any aerosol direct effects while the sixth experiment includes this effect. Thus, the difference between experiments 5 and 6 evaluates changes in cloud liquid water path and whole and clear sky forcing associated with the absorption and scattering of aerosols.

The aerosol scheme in the LMD-Z model used a massbased scheme and an assumed size distribution for each aerosol type with the sulfur-cycle as described by Boucher et al. (2002) and formulations for sea-salt, black carbon, organic matter, and dust described by Reddy et al. (2005). In CAM-Oslo, the background aerosol consists of 5 different aerosol types each with multiple components that are ei- ther externally or internally mixed dust or sea salt modes which are represented by multimodal log-normal size distributions. Sulfate, OC and BC modify these size distributions as they become internally mixed with the background aerosol (Iversen and Seland, 2002; Kirkevåg and Iversen, 2002; Storelvmo et al., 2006). In the CCSR model, the sulfate aerosol scheme follows that described in Takemura et al (2002). 50\% of fossil fuel BC is treated as externally mixed, while the other carbonaceous particles are internally mixed with sulfate aerosol. Soil dust and sea salt mixing ratios are followed in several size bins (Takemura et al., 2002).

\section{Results}

Table 3 summarizes the outgoing shortwave radiation for the whole sky and clear sky for the difference between the present day simulations and pre-industrial simulations for each model and each experiment. The table also shows the difference in cloud forcing between the present day and preindustrial runs. The cloud forcing is defined as the difference between the whole sky and clear sky outgoing shortwave radiation. Below, we discuss the results from each experiment in turn.

\subsection{Experiment 1: Influence of cloud variability}

Figure 1 shows a latitude/longitude graph of the grid-average total liquid water path predicted by the CAM-Oslo and CCSR models for experiment 1a. We also show the inferred liquid water path from the SSMI satellite instrument (Weng and Grody, 1994; Greenwald et al., 1993) and from the MODIS satellite instrument (Platnick et al., 2003). We note that the liquid water path for the LMD-Z model was not available as a separate diagnostic, and hence we plot the 


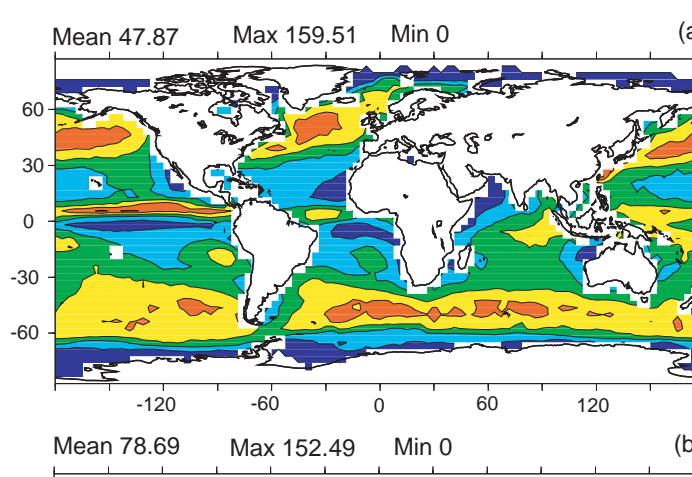

(a) Mean 47.88 $\quad \operatorname{Max} 416.18 \quad \operatorname{Min} 0$

(e)

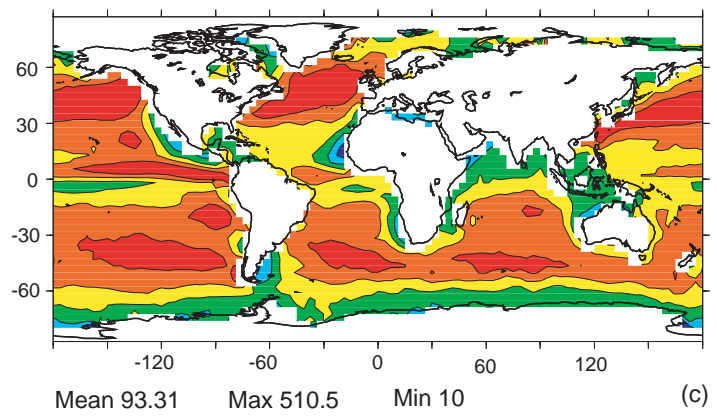

(b) Mean $93.2895 \quad \operatorname{Max} 751.53 \quad \operatorname{Min} 0$
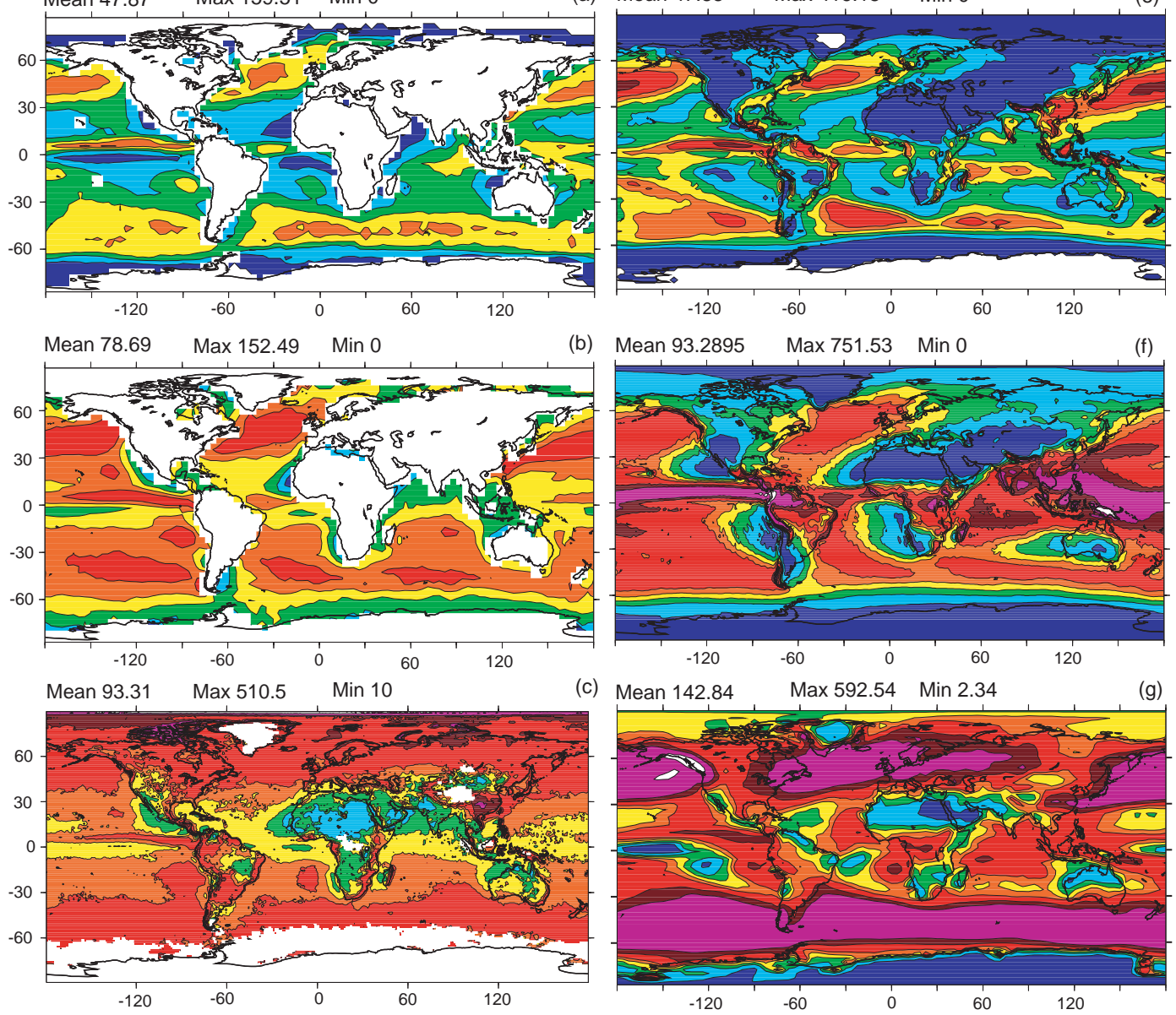

Mean $142.84 \quad$ Max 592.54 Min 2.34

(g)
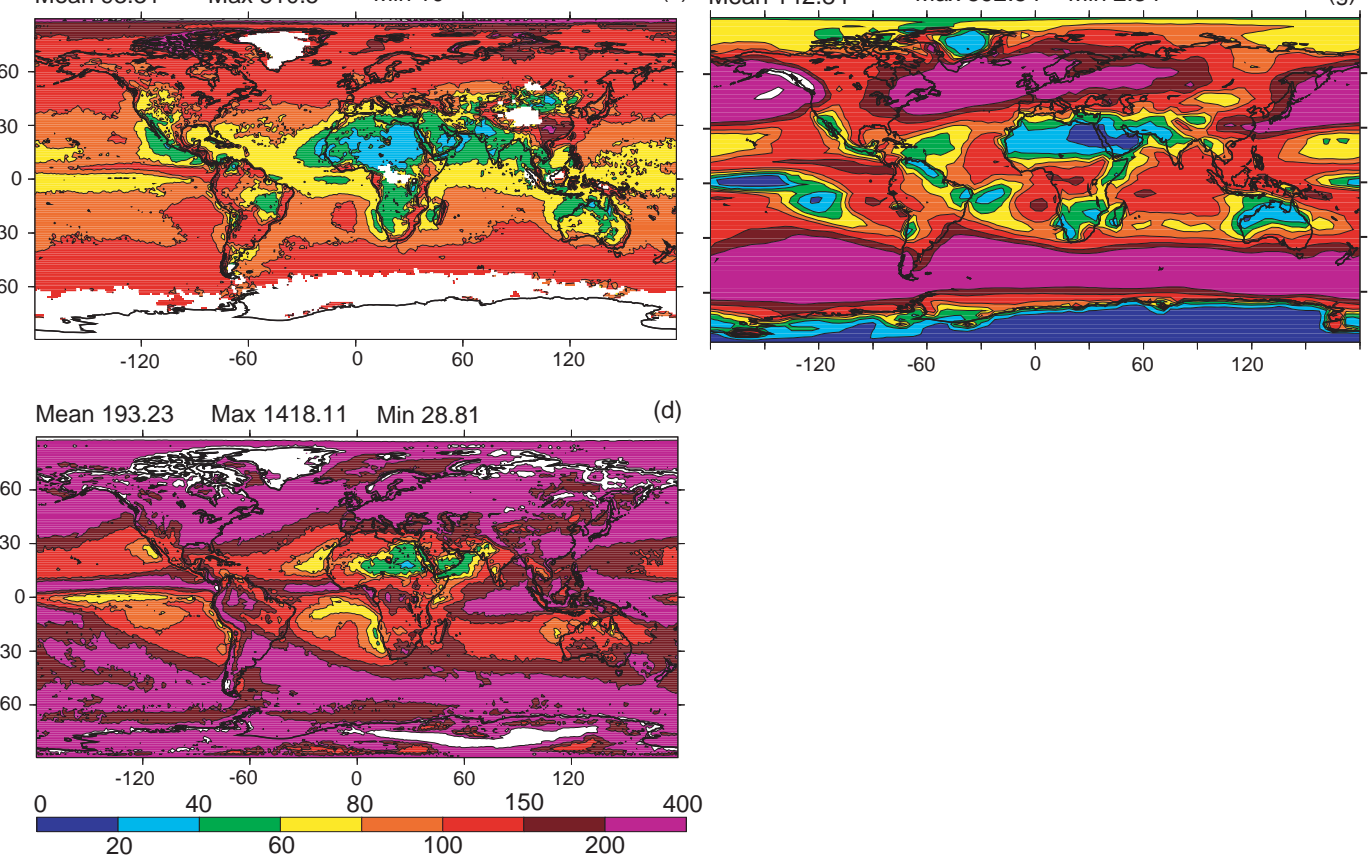

Fig. 1. Annual average cloud liquid water path in $\mathrm{g} \mathrm{m}^{-2}$ as inferred from the SSM/I satellite instrument by (a) Weng and Grody (1993) and by (b) Greenwald et al. (1993) and (c) as inferred from the MODIS instrument for T $>260^{\circ}$ (Platnick et al., 2003). Panel (d) shows the liquid plus ice path from MODIS, while panels (e) and (f) show the liquid water path from the CAM-Oslo and CCSR models in experiment 1a, respectively. Panel (g) shows the liquid plus ice path in the LMD-Z model in experiment 1a.

sum of the liquid and ice water path for this model together with the summed liquid and ice water path from MODIS. Figure 2a shows the global average liquid water and ice water path for each of the present day experiments as well as the liquid water path for the CAM-Oslo and CCSR models. The change in liquid water path between the present day and pre-industrial simulations is shown in Fig. 2b. Here, and in the following, we assume that the change in liquid and ice water path in the LMD-Z model is primarily due to the change in liquid water path. This seems likely since the changes introduced in the present day and pre-industrial simulations were only applied to the liquid water field and 


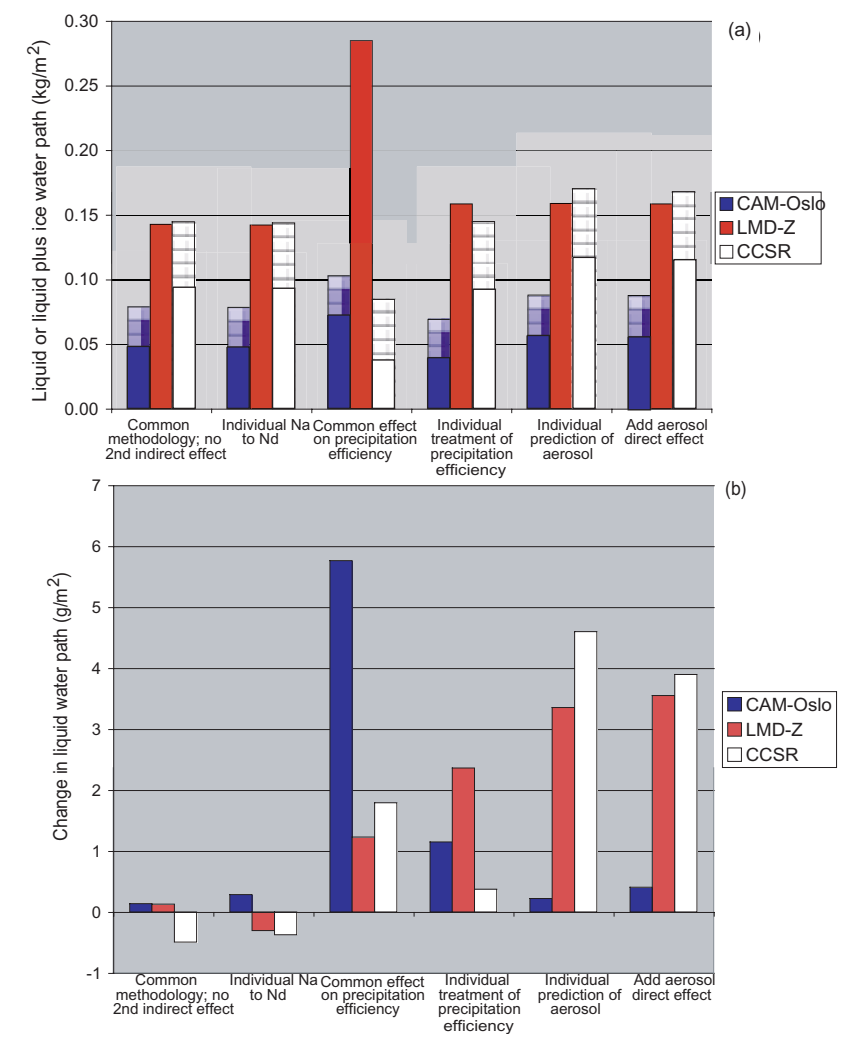

Fig. 2. (a) Global average present day liquid plus ice water path in the three models in each experiment. The solid portion of the bar graphs for the CAM-Oslo and CCSR models represents their liquid water path, while the horizontally hatched portion of the bar graph represents their ice water path. The LMD model results are only available for the liquid plus ice water path. (b) Global average change in liquid water path between present-day and preindustrial simulations in the three models in each experiment.

since in the CAM-Oslo and CCSR models the change in total liquid and ice water is similar to the change in total liquid water for each of the experiments. The global average liquid water path in experiment 1a ranges from $0.05 \mathrm{~kg} \mathrm{~m}^{-2}$ for CAM-Oslo to $0.09 \mathrm{~kg} \mathrm{~m}^{-2}$ for CCSR. The total liquid plus ice water path in experiment 1a ranges from $0.08 \mathrm{~kg} \mathrm{~m}^{-2}$ in the CAM-Oslo model to about $0.14 \mathrm{~kg} \mathrm{~m}^{-2}$ for both the CCSR and LMD-Z models. The cloud forcing in the present day simulations should reflect these different values in liquid water path as well as the predicted droplet effective radius in each model. Figure 3 shows the predicted droplet number concentrations from the model level closest to $850 \mathrm{hPa}$, while Fig. 4 shows the predicted effective radius near $850 \mathrm{hPa}$ from all the models. The droplet number concentration predicted in the CAM model near $850 \mathrm{mb}$ is somewhat higher than that in the LMD-Z and CCSR models $\left(159 \mathrm{~cm}^{-3}\right.$ versus $120 \mathrm{~cm}^{-3}$ and $119 \mathrm{~cm}^{-3}$, respectively). A somewhat larger cloud droplet number in CAM is expected, since the specified aerosol concentrations had a scale height of $2 \mathrm{~km}$, and
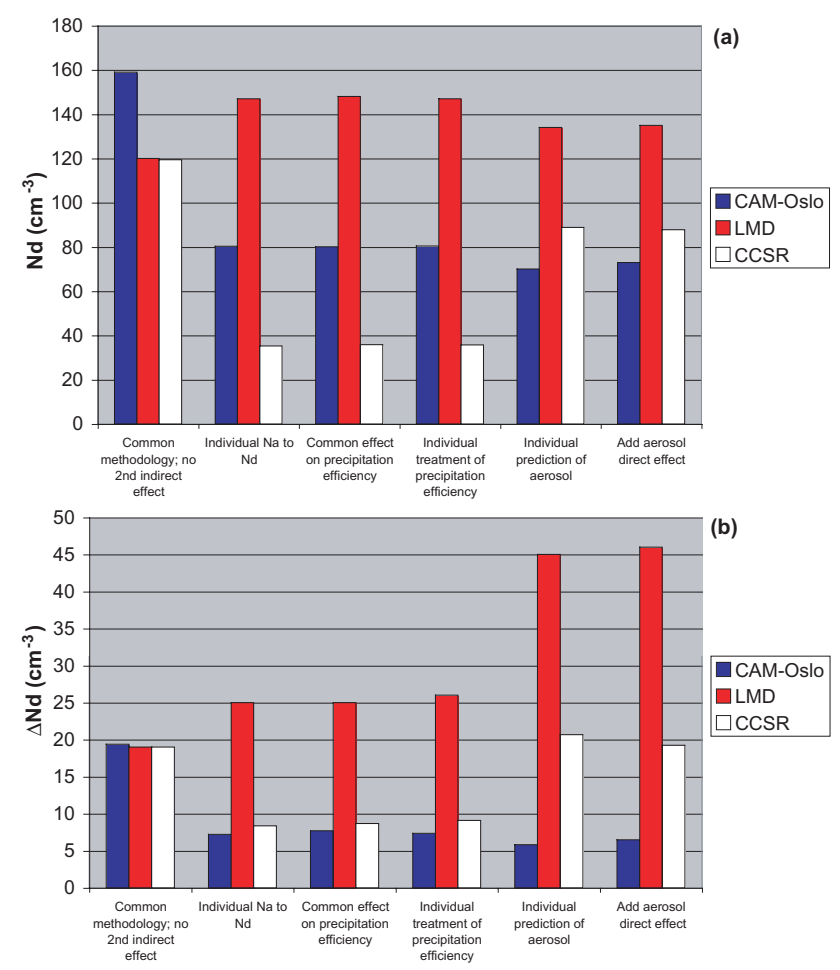

Fig. 3. (a) Global average present day cloud droplet number concentration near $850 \mathrm{hPa}$ and (b) global average change in cloud droplet number concentration near $850 \mathrm{hPa}$ between the presentday and pre-industrial simulations for each model in each experiment. The actual level plotted is $867 \mathrm{hPa}$ for CAM-Oslo, $848 \mathrm{hPa}$ for LMD-Z, and $817 \mathrm{hPa}$ for CCSR/NIES/FRCGC.

the nearest level of the CAM-Oslo model to $850 \mathrm{hPa}$ is actually at about $867 \mathrm{hPa}$. The smaller liquid water path in CAMOslo, however, leads to an effective radius in the model near $850 \mathrm{hPa}$ which is similar to that in the LMD-Z model $(7.4 \mu \mathrm{m}$ in CAM-Oslo versus $7.2 \mu \mathrm{m}$ in LMD-Z). The effective radius in the CCSR model near $850 \mathrm{hPa}$ is somewhat larger, $10.4 \mu \mathrm{m}$, but this larger effective radius is expected given the higher liquid water path at this level than that in the CAMOslo model $\left(0.02 \mathrm{~kg} \mathrm{~m}^{-2}\right.$ in CCSR versus $0.009 \mathrm{~kg} \mathrm{~m}^{-2}$ in CAM-Oslo).

The similar droplet effective radii in each of the models lead to similar radiative fluxes. The shortwave cloud forcing (calculated as the difference between the whole sky net outgoing shortwave radiation and the clear sky net outgoing shortwave radiation) for the present-day simulation (experiment 1a) for the three models is: $-51 \mathrm{Wm}^{-2}$ for CAMOslo, $-62 \mathrm{Wm}^{-2}$ for LMD-Z, and $-52 \mathrm{Wm}^{-2}$ for CCSR (see Fig. 5a).

The change in net outgoing whole sky shortwave radiation between present day and pre-industrial simulations for experiment 1 is a measure of the first indirect effect in these models, since direct aerosol radiative heating effects were not included and since the autoconversion rate for precipitation 

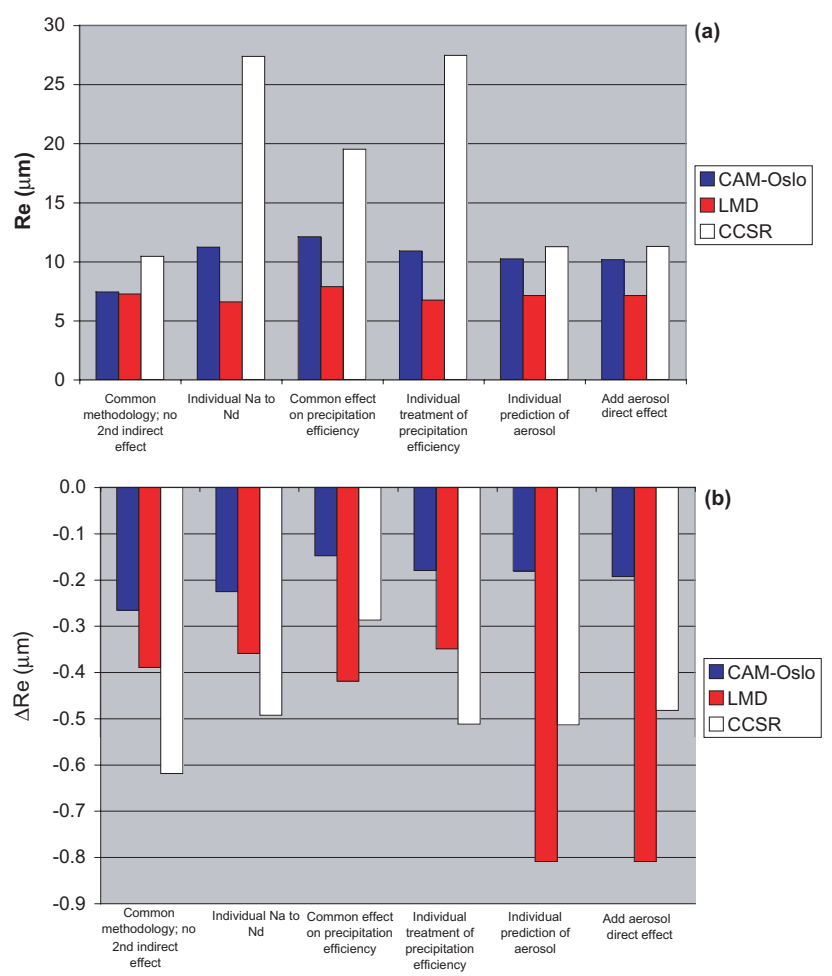

Fig. 4. (a) Global average present day cloud droplet effective radius near $850 \mathrm{hPa}$ and (b) global average change in cloud droplet effective radius near $850 \mathrm{hPa}$ between the present-day and pre-industrial simulations for each model in each experiment. The actual level plotted is $867 \mathrm{hPa}$ CAM-Oslo, $848 \mathrm{hPa}$ for LMD-Z, and $817 \mathrm{hPa}$ for CCSR.
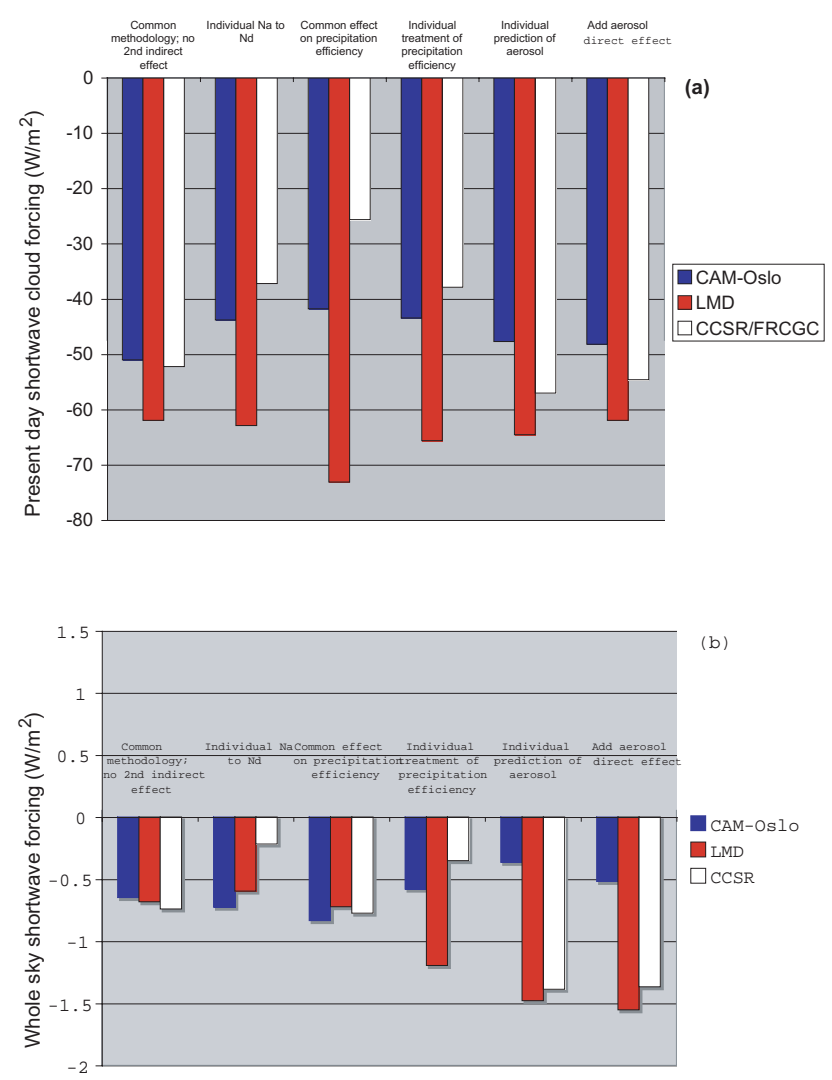

Fig. 5. (a) Global average present day short wave cloud forcing and (b) the global average change in whole sky net outgoing shortwave radiation between the present-day and pre-industrial simulations for each model in each experiment.

\subsection{Experiment 2: Influence of CDNC parameterization}

Experiment 2 differs from experiment 1 because it allows each model to choose their own parameterization for converting the fixed aerosol concentrations and size distributions to droplet number concentrations. As a result the present day droplet number in experiment 2 increases from $120 \mathrm{~cm}^{-3}$ near $850 \mathrm{hPa}$ in experiment 1 to $147 \mathrm{~cm}^{-3}$ in experiment 2 in the LMD-Z model, but decreases from $159 \mathrm{~cm}^{-3}$ and $119 \mathrm{~cm}^{-3}$ in experiment 1 to $80 \mathrm{~cm}^{-3}$ and $35 \mathrm{~cm}^{-3}$ in experiment 2 in the CAM-Oslo and CCSR models, respectively. Because the change in the liquid water path is small, the change in the effective radius between the present day simulations for experiment 2 and experiment 1 is in the opposite direction: smaller in the LMD-Z model in experiment 2 compared to experiment 1 and larger in the CAM-Oslo and CCSR models (Fig. 4a). Nevertheless, the change in effective radius between the present day and pre-industrial simulations in experiment 2 is nearly the same as that in experiment 1 for the LMD-Z and CAM-Oslo models (Fig. 4b) and the resulting change in net outgoing shortwave radiation between the present day and pre-industrial simulations 
is also nearly the same as for experiment 1 for the LMD$\mathrm{Z}$ and CAM-Oslo models (Table 3). The larger liquid water path in the CCSR model together with its smaller predicted cloud droplet number concentration (Fig. 3a) in experiment 2 compared to experiment 1 leads to a larger effective radius in the present day in experiment 2 (Fig. 4a). This leads to a change in effective radius for the CCSR model in experiment 2 that is about $0.1 \mu \mathrm{m}$ smaller than the change in effective radius in experiment 1 (Fig. 4b). The difference in net outgoing shortwave radiation between the present day and pre-industrial simulations changes from $-0.65 \mathrm{Wm}^{-2}$ to $-0.73 \mathrm{Wm}^{-2}$ in the CAM-Oslo models, respectively, but is slightly reduced from $-0.68 \mathrm{Wm}^{-2}$ to $-0.60 \mathrm{Wm}^{-2}$ in the LMD-Z model and more significantly reduced, from $-0.74 \mathrm{Wm}^{-2}$ to $-0.22 \mathrm{Wm}^{-2}$ in the CCSR model, consistent with the smaller change in effective radius in this model. Even though the global average change in net outgoing shortwave radiation for the CAM-Oslo model is similar in experiment 1 and experiment 2 , the spatial patterns of the cloud forcing differ. The Abdul-Razzak and Ghan (2000) cloud droplet parameterization used in experiment 2 leads a stronger forcing in the major biomass burning regions in Africa and South America than does the Boucher and Lohmann (1995) parameterization used in experiment 1. The CCSR model also used the Abdul-Razzak and Ghan (2000) parameterization and shows a similar spatial pattern.

\subsection{Experiment 3: Influence of cloud lifetime effect}

The third experiment introduced the effect of aerosols on the precipitation efficiency, specifying the use of the Khairoutdinov and Kogan (2000) formulation for autoconversion. The liquid water path in the present day simulations for experiment 3 increases compared to experiment 2 in the CAMOslo and LMD-Z models but the increase is much larger for the LMD-Z model than that for the CAM-Oslo model (compare experiment 3 with experiment 2 in Fig. 2a). The liquid water path decreases in the CCSR model. These contrasting responses in liquid water path are related to the droplet number concentrations in each model. While the LMD-Z and CAM-Oslo models have droplet number concentrations that, on average, vary from 75 to $150 \mathrm{~cm}^{-3}$, the CCSR model has droplet number concentrations that are as low as $15 \mathrm{~cm}^{-3}$ near the tops of clouds. Figures $6 \mathrm{a}$ and $\mathrm{b}$ show the autoconversion rates for the Khairoutdinov and Kogan (2000) scheme and the Sundquist (1978) scheme for droplet number concentrations of $100 \mathrm{~cm}^{-3}$ and $15 \mathrm{~cm}^{-3}$, respectively. The scale for the liquid water content in Fig. $6 \mathrm{~b}$ emphasizes the region of liquid water contents that are typical is the models. The autoconversion rate in the Khairoutdinov and Kogan (2000) scheme for droplet numbers similar to those predicted in the LMD-Z and CAM-Oslo models is significantly smaller than that from the Sundquist (1978) scheme specified in experiments 1 and 2, while the rates for the Khairoutdinov and Kogan (2000) scheme are larger than those from
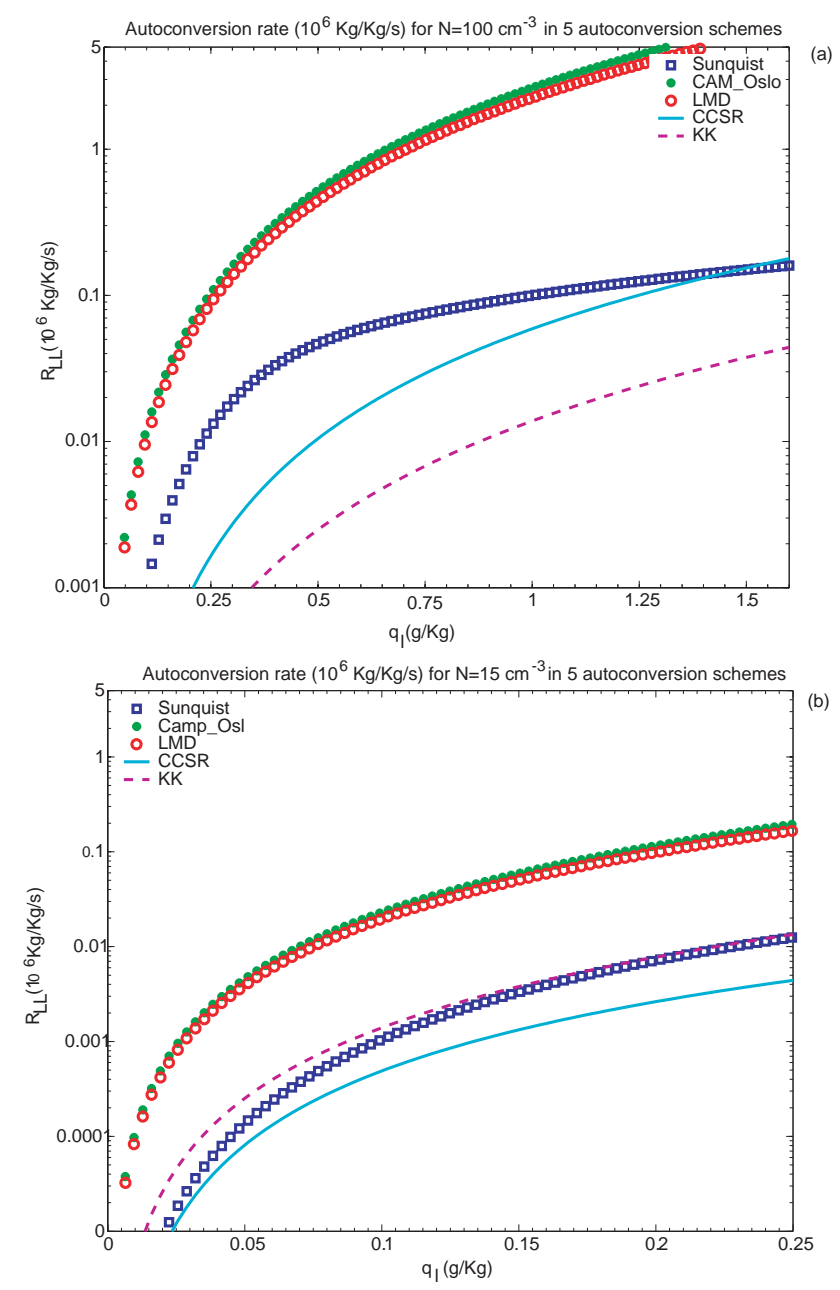

Fig. 6. Autoconversion rates (in $10^{6} \mathrm{~kg} / \mathrm{kg} / \mathrm{s}$ ) as a function of liquid water mixing ratio $(\mathrm{g} / \mathrm{kg})$ for different autoconversion schemes. The calculations assumed a droplet number concentration of (a) $100 \mathrm{~cm}^{-3}$ and (b) $15 \mathrm{~cm}^{-3}$. Note change of horizontal scale.

the Sundquist (1978) scheme for droplet number concentrations and liquid water contents similar to those in the CCSR model. The present-day cloud droplet number concentrations remain similar to the values predicted in experiment 2 , as expected, since the cloud droplet parameterization was not changed (Fig. 3a). There is an increase in the present day effective radius near $850 \mathrm{hPa}$ in experiment 3 for the CAM-Oslo and LMD-Z models compared to experiment 2 which is associated with the increase in liquid water path (Fig. 4a). The decrease in the present-day liquid water path in the CCSR model in experiment 3 compared to experiment 2 leads to a decrease in the cloud droplet effective radius near $850 \mathrm{hPa}$ as expected (compare Fig. 2a and Fig. 4a).

The change in grid average liquid water path between the present day and pre-industrial simulations is a measure of how important the changes in liquid water content, cloud height and cloud fraction that are induced by changes in 

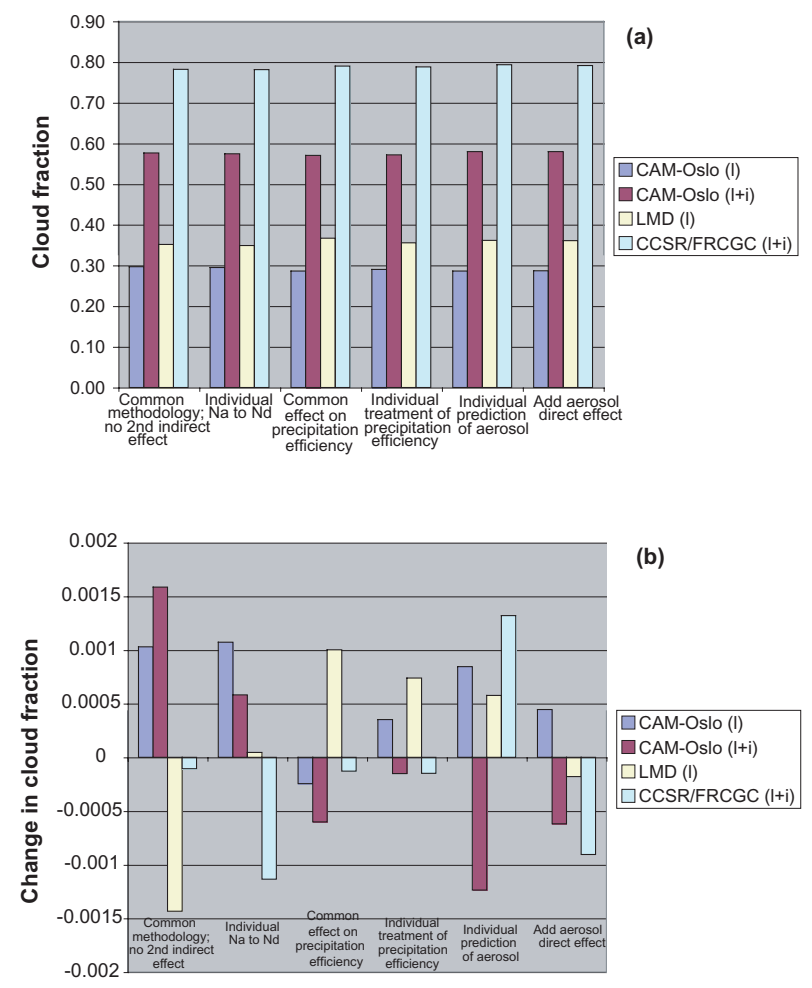

Fig. 7. (a) Global average present-day liquid or liquid plus ice cloud fraction and (b) global average change in cloud fraction between the present-day and pre-industrial simulations for each model in each experiment.

precipitation efficiency are in each model. The change in liquid water path between present day and pre-industrial simulations in the CAM-Oslo model, $0.0057 \mathrm{~kg} \mathrm{~m}^{-2}$, is a factor of 4.7 and 3.2 larger than that in the LMD-Z and CCSR models, respectively, but all models predict an increase in global average liquid water path, consistent with other model simulations of the $2^{\text {nd }}$ indirect effect (i.e. Lohmann et al., 2000; Jones et al., 2001; Rotstayn and Penner, 2001; Ghan et al., 2001; Menon et al., 2002; Quaas, et al., 2004; Rotstayn and Liu, 2005; Takemura et al., 2005). Figure 7 shows the global average cloud fraction and change in cloud fraction between present day and pre-industrial simulations for each model and each experiment. We present the cloud fractions for liquid and liquid plus ice for the CAM-Oslo model, but only that for liquid water for the LMD-Z model and only that for liquid plus ice for the CCSR model. The present day cloud cover in each model is similar for all experiments (Fig. 7a), but the change in cloud fraction between the present day and pre-industrial simulations is highly variable, though small (Fig. 7b). The change in cloud fraction associated with the introduction of the effect of aerosols on the precipitation efficiency is smaller (in absolute value) than that in experiment's 1 and 2 and it decreases in both CAM-Oslo and CCSR while it increases in the LMD-Z model. Since the absolute value of the changes between present day and pre-industrial simulations in experiments 1 and 2 are at least as large or larger than the change in experiment 3 , the changes noted in experiment 3 must be considered to be within the natural variability of the model. Given the nature of the cloud fraction parameterizations in each of the models (Sect. 2), this is, perhaps, not surprising. Significant improvements in model procedures for predicting cloud fraction would be needed to determine whether the models can reproduce the effects on cloud fraction recently reported by Kaufmann et al. (2005).

The changes in liquid water path and effective radius result in a slightly larger change in net outgoing shortwave radiation between the present day and pre-industrial simulations in the CAM-Oslo and the LMD-Z models between experiment 2 and experiment 3 , i.e. from $-0.73 \mathrm{Wm}^{-2}$ to $-0.83 \mathrm{Wm}^{-2}$ and from $-0.60 \mathrm{Wm}^{-2}$ to $-0.72 \mathrm{Wm}^{-2}$, respectively. Thus, the 2nd indirect effect amplifies the radiative forcing in these models by only $22 \%$ in both models. The change in net outgoing shortwave radiation in the CCSR model is significantly larger in experiment 3 compared to experiment 2, changing from $-0.22 \mathrm{Wm}^{-2}$ to $-0.77 \mathrm{Wm}^{-2}$. Thus, adding the $2 \mathrm{nd}$ indirect effect in this model amplifies the change in cloud forcing by more than a factor of 3 .

\subsection{Experiment 4: Influence of autoconversion scheme}

In experiment 4, each model introduced their own formulation for precipitation efficiency. These formulations were presented in Sect. 2.1 and are displayed as a function of liquid water mixing ratio for a droplet number concentration of $100 \mathrm{~cm}^{-3}$ in Fig. $6 \mathrm{a}$ and for a droplet number concentration of $15 \mathrm{~cm}^{-3}$ in Fig. 6b. Figure 6a shows that the Khairoutdinov and Kogan (2000) formulation removes cloud water much more slowly than does the formulation preferred in the CAM-Oslo and LMD-Z models. This implies a decrease in the liquid water path between experiment 3 and experiment 4 in LMD-Z and CAM-Oslo, and this is indeed the case (Fig. 2a). Nevertheless, the change in liquid water path between present day and pre-industrial simulations is larger in the LMD-Z model than it was in experiment 3, but smaller in the CAM-Oslo model. This is consistent with the much larger change in cloud droplet number concentration near $850 \mathrm{hPa}$ in the LMD-Z model compared to that in the CAM-Oslo model (Fig. 3b) together with the much more sensitive change in precipitation formation rate for both models in experiment 4 compared to experiment 3 (Fig. 6a). The difference in the change in net outgoing shortwave radiation between present day and pre-industrial simulations (Fig. 5b) between experiment 4 and experiment 3 follows the predicted changes in liquid water path (Fig. 2b) and effective radius (Fig. 4b) for LMD-Z and CAM-Oslo. Thus, even though the change in effective radius is larger (smaller) in CAM-Oslo (LMD-Z) in experiment 4 compared to experiment 3 , it is the change in liquid water path between the present day and pre-industrial simulations which is smaller (larger) in CAM- 
Olso (LMD-Z) in experiment 4 compared to experiment 3 which dominates the change in net outgoing shortwave radiation.

The CCSR model has a much smaller droplet number concentration, especially at the upper levels in the cloud (about $15 \mathrm{~cm}^{-3}$, on average). The autoconversion rate normally used in the CCSR model for $N_{d}=15 \mathrm{~cm}^{-3}$ is smaller than that for the Khairoutdinov and Kogan (2000) scheme (Fig. 6b) and, as a result, the liquid water path in experiment 4 is larger than it was in experiment 3 (Fig. 2a). The change in liquid water path in experiment 4 is much smaller than the change in liquid water path in experiment 3 , and, in fact, the small change in experiment 4 is actually within the noise of the model (since it is similar in magnitude to the change in liquid water path in experiments 1 and 2). Nevertheless, the change in effective radius in experiment 4 in this model is significantly larger than that in experiment 3 (i.e. $-0.51 \mu \mathrm{m}$ near $850 \mathrm{hPa}$ in experiment 4 compared to $-0.29 \mu \mathrm{m}$ in experiment 3 ). The change in net outgoing shortwave radiation between the present day and pre-industrial simulations is dominated by the change in liquid water path rather than the change in effective radius. Thus the change in net outgoing shortwave radiation between the present day and preindustrial simulations is smaller in experiment 4 than it was in experiment 3 .

\subsection{Experiment 5: Influence of calculated aerosol distribu- tion}

In experiment 5 , each model calculated the radiative forcing using their individual precipitation formation schemes as well as their individual aerosol concentrations, but with common specified sources. The difference in the change in net outgoing shortwave radiation between the present day and pre-industrial simulations is larger between experiments 4 and 5 for both the CAM-Oslo and CCSR models than between any of the other pairs of experiments. The change in net outgoing shortwave radiation for the CAMOslo model decreases from $-0.58 \mathrm{Wm}^{-2}$ to $-0.36 \mathrm{Wm}^{-2}$ while in the CCSR model it increases from $-0.35 \mathrm{Wm}^{-2}$ to $-1.39 \mathrm{Wm}^{-2}$. In the LMD-Z model, the change in net outgoing shortwave radiation in going from experiment 3 to experiment 4 is somewhat larger $\left(-0.47 \mathrm{Wm}^{-2}\right)$ than it is in going from experiment 4 to experiment $5\left(-0.29 \mathrm{Wm}^{-2}\right)$ but the change between experiment 4 and experiment 5 is still significant relative to the other changes introduced in these experiments. These changes are caused by large changes in the change in droplet concentrations (Fig. 3b) between the present day and pre-industrial simulations for experiment 5 compared to experiment 4 , which are simply due to the large changes in present day and pre-industrial aerosols calculated by each of the models. Thus, within any one model, the change in net outgoing shortwave radiation is most sensitive to the calculation of individual aerosol fields than to any of the other parameters in the cloud scheme. The change in cloud droplet number concentration and effective radius between the present day and pre-industrial simulations is largest in the LMD-Z model followed by the changes in the CCSR model. The change in net outgoing shortwave radiation for the LMD-Z model $\left(-1.48 \mathrm{Wm}^{-2}\right)$ is also larger than that for the CCSR model $\left(-1.39 \mathrm{Wm}^{-2}\right)$ even though the liquid water path change is larger in the CCSR model. Apparently the larger change in effective radius in the LMD$\mathrm{Z}$ model outweighs the larger change in liquid water path in the CCSR model. It is interesting that the larger changes in droplet number concentrations predicted for the difference between the present day and pre-industrial simulations in this experiment in the LMD-Z and CCSR models have led to a larger increase in the average change in liquid water path and cloud fraction in the CCSR model than that in the LMD-Z model, and this leads to a larger difference in the response of the net outgoing shortwave radiation between the present day and pre-industrial simulation between experiments 4 and 5 in CCSR. The CCSR autoconversion scheme is more sensitive to changes in droplet number concentrations than is the LMD-Z scheme and this explains the more sensitive response of the liquid water path in this model. In addition, the inclusion of the collection of cloud droplets by falling rain (accretion) in this model enhances any sensitivity of the liquid water path to changes in droplet number. The change in the droplet concentration near $850 \mathrm{hPa}$ is somewhat smaller in experiment 5 compared to that in experiment 4 in the CAMOslo model as is the change in the liquid water path, while the change in the effective radius is similar to that in experiment 4. As a result the change in net outgoing shortwave radiation is smaller for this model in experiment 5 than it is in experiment 4.

\subsection{Experiment 6: Influence of aerosol direct effect}

Experiment 6 was designed to determine the effect of including the heating by aerosols on clouds in the models. Including this effect has a large impact on the change in cloud forcing (see Table 3) between the present day and pre-industrial simulations in all the models even though the change in the liquid water path (Fig. 2b) and the effective radius (Fig. 4b) is similar in both experiments 5 and 6 . The change in absorbed solar radiation between the present day and pre-industrial simulations was $0.74 \mathrm{Wm}^{-2}, 1.37 \mathrm{Wm}^{-2}$, and $3.86 \mathrm{Wm}^{-2}$ in CAM-Oslo, LMD-Z, and CCSR, respectively, but the change in cloud fraction is smaller than that which can be explained by natural variability in the models (Fig. 7b) so the effect of this absorbed radiation on clouds is apparently quite small in these models. The change in net outgoing shortwave radiation between the present day and the pre-industrial simulations is slightly larger in experiment 6 compared to experiment 5 in CAM-Oslo and LMD$\mathrm{Z}$, because the change in net outgoing clear sky radiation is fairly large in these models in experiment $6\left(-0.57 \mathrm{Wm}^{-2}\right.$ and $-1.03 \mathrm{Wm}^{-2}$, respectively). The change in net outgoing 
radiation in the CCSR model, on the other hand, is slightly smaller in experiment 6 than it was in experiment 5 despite a large clear sky forcing $\left(-1.17 \mathrm{Wm}^{-2}\right)$. This is mainly caused by a decrease in the change in liquid water path (Fig. 2b) in this model which differs from the response of the other models to the change in radiative heating induced by the direct forcing of the aerosols. The clear sky shortwave forcing in the CAM-Oslo, LMD-Z, and CCSR models is -0.57 , -1.03 and $-1.17 \mathrm{Wm}^{-2}$, respectively. When these values are subtracted from the respective whole sky forcing values $\left(-0.52 \mathrm{Wm}^{-2},-1.55 \mathrm{Wm}^{-2}\right.$, and $-1.37 \mathrm{Wm}^{-2}$, respectively), all models result in a significant decrease in the (negative) change in cloud forcing associated with experiment 5 (see Table 3). Thus, the large changes in cloud forcing between experiments 5 and experiments 6 shown in Table 3 result from a combination of the changes in liquid water path and the large negative values in the change in clear sky outgoing radiation in experiment 6 .

\section{Discussion and conclusions}

The purpose of this paper was to compare the results from several GCMs in a set of controlled experiments in order to determine the most important uncertainties in the treatment of aerosol-cloud interactions. We started with a controlled experiment with a fixed aerosol distribution and prescribed CDNC parameterization and an autoconversion scheme that only depends on the in-cloud liquid water mixing ratio (not on the droplet number or cloud droplet effective radius). This experiment showed that the modeled liquid water path varied significantly (by almost a factor of two) between the basic GCMs. This variation is partly explained by the different cloud fraction schemes in the models and may also be associated with other basic differences in the models. All models show patterns of liquid or liquid plus ice water path that are similar to satellite observations, but the difference between global average liquid water path or liquid plus ice water path (for LMD-Z) and that measured by MODIS, for example, is $-49 \%,-26 \%$, and $-0.1 \%$ for CAM-Oslo, LMD-Z, and CCSR, respectively. The comparison to satellite liquid water path is improved to $-39 \%$ and $-18 \%$ for the CAM-Oslo and LMD-Z models, respectively, when using their own aerosols and cloud microphysics schemes in experiment 6 , but is degraded to $22 \%$ in the CCSR model.

The first experiment did not result in large changes in liquid water path between the present day and pre-industrial simulations, as expected, but the differences in present-day liquid water path among the models lead to substantial differences in the effective radii of clouds near $850 \mathrm{hPa}$, and substantial differences in the change in effective radius between the present day and pre-industrial simulations. Nevertheless, compensations within the radiation and cloud fraction schemes lead to very similar changes in net outgoing shortwave radiation in this experiment.
In the second experiment each modeler used their own CDNC parameterization. But these separate parameterizations led to only small changes in the global average change in net outgoing shortwave radiation in the CAM-Oslo and LMD-Z models, with more substantial changes in the CCSR model (i.e., a reduction of $0.5 \mathrm{Wm}^{-2}$ ). Thus, the method of parameterization of CDNC can have a large impact on the calculation of the first indirect effect in at least some models, though it was not a primary uncertainty in the determination of the global average first indirect effect in the study by Chen and Penner (2005).

The third experiment introduced the effect of changes in precipitation efficiency for each of the models. The total liquid water path increased in both the CAM-Oslo and LMD$\mathrm{Z}$ models which was expected because the specified autoconversion parameterization rate in experiments 1 and 2 was much stronger than that specified in experiment 3 (compare Sundquist, 1978, scheme in Fig. 6 with that from Khairoutdinov and Kogan, 2000). But the change in liquid water path was much larger for LMD-Z (increase by almost a factor of 2) than it was for CAM. Figure 6 shows that a model with higher liquid water mixing ratio should be more sensitive to the change in autoconversion parameterization. This is indeed the case. The LMD-Z model has a larger liquid water path than the CAM-Oslo model, and its liquid water path in the present-day simulation increases more when using the Khairoutdinov and Kogan (2000) scheme. However, even though the CCSR model also has a larger liquid water path than does the CAM-Oslo model, its present day liquid water path in experiment 3 is actually smaller than that in experiment 2. Since the CAM-Oslo and LMD-Z models did not include collection of droplets by falling rain and snow in these experiments, they are apparently less sensitive to the autoconversion parameterization than is the CCSR model which includes these additional loss processes.

The present day minus pre-industrial change in net outgoing shortwave radiation increases (becomes more negative) in all models in going from experiment 2 to 3 . The relative increase is small (on average only $22 \%$ ) for the CAMOslo and LMD-Z models but it is more than a factor of 3 for the CCSR model. Thus, even for the rather large change in autoconversion rates (Fig. 6), the 2nd indirect effect is rather small in two of the models. Nevertheless, when modelers' introduced their own autoconversion schemes, in experiment 4, both larger (LMD-Z) and smaller (CAM-Oslo) changes in net outgoing shortwave radiation compared to experiment 3 are apparent. Even though both the LMD-Z and CAM-Oslo autoconversion schemes are more sensitive to changes in droplet concentration than that expected using the Khairoutdinov and Kogan (2000) scheme, the larger liquid water path in the LMD-Z model causes it to respond significantly to this change in autoconversion rate, while the CAMOslo model change in liquid water path and net outgoing shortwave radiation in experiment 4 is actually smaller than that in experiment 3 . This result is consistent with the much 
smaller change in liquid water path predicted in experiment 4 in the CAM-Oslo model relative to experiment 3 which was caused by the fact that collection of cloud droplets by falling rain and snow was included in experiment 4 , but not in experiment 3. The CCSR model had a smaller change in liquid water path in experiment 4 compared to experiment 3 which apparently outweighs its change in cloud droplet effective radius which was much larger in experiment 4 than it was in experiment 3 . This leads to a smaller change in net outgoing radiation in this model in experiment 4 compared to experiment 3 , similar to the response of the CAM-Oslo model.

In experiment 5 , prescribed aerosol sources were specified, but each modeler used their own method to compute aerosol concentrations (as well as their own method for the CDNC parameterization and autoconversion parameterization). This change introduced the largest differences in the change in net outgoing shortwave radiation between the models. Thus, the prediction of aerosol number concentration appears to introduce the largest uncertainty in calculation of the aerosol indirect effect among these models.

In experiment 6 , we introduced the aerosol heating profile within the models, however, the average liquid water path for each of the models in experiment 6 was very similar to that in experiment 5. Nevertheless, the difference in liquid water path between the present day and pre-industrial simulations was somewhat larger in both the LMD-Z and CAMOslo models than it was in experiment 5 . The change in the liquid water path in the CCSR model was somewhat smaller than that in experiment 5 . These relative changes between the liquid water path change in experiment 5 and experiment 6 are smaller than the natural variability within the models.

It is of interest to put the predicted cloud forcing from experiment 5 into the context of other model studies for indirect forcing. The models used to provide results for the CCSR model and the LMD-z model are the same as those reported in the model intercomparison of Lohmann and Feichter (2005) (i.e. they are the models described and used in the studies of Quaas et al. (2004) and Takemura et al. (2005), while the CAM-Oslo model was updated to use the CAM2 "host" meteorology rather than the NCAR CCM3 meteorology as described in Storelvmo et al. (2006). This change was significant since CAM2 has higher liquid water path compared to CCM3. It also uses a maximum-random cloud overlap scheme rather than a random overlap scheme. In addition, organic carbon was added to the CAM-Oslo simulation, and the $\mathrm{CCN}$ activation scheme was changed from prescribed supersaturations and look-up tables to the Abdul-Razzak and Ghan (2002) scheme. One further change is that all the models used here used the emissions from the AEROCOM "B" intercomparison (Dentener et al., 2006), except that dust and sea salt were prescribed in the CAM-Oslo model.

Values for cloud forcing reported for the LMD-z model and for the CCSR model in Lohmann and Feichter (2005) (about $-1.2 \mathrm{Wm}^{-2}$ and $-0.9 \mathrm{Wm}^{-2}$, respectively) are some- what smaller than the cloud forcing reported here for experiment $5\left(-1.35 \mathrm{Wm}^{-2}\right.$ and $\left.-1.40 \mathrm{Wm}^{-2}\right)$, presumably because of the change in emissions. The range of cloud forcing values found here for experiment $5\left(-0.31 \mathrm{Wm}^{-2}\right.$ to $-1.40 \mathrm{Wm}^{-2}$ ) includes one value smaller than any summarized in Lohmann and Feichter, but, since that study quoted values as large as almost $-3.0 \mathrm{Wm}^{-2}$, the largest value reported here is at least a factor of 2 less than the values in Lohmann and Feichter. While a standard deviation makes little sense for a sample of only 3 models, if we formally compute one, we get a value of $0.6 \mathrm{Wm}^{-2}$, similar to the value quoted in Lohmann and Feichter (2005).

As noted above, one of the most important uncertainties in the model prediction of aerosol indirect effects is the model prediction of aerosols. In that sense, we can compare the lifetimes for aerosols reported in Textor et al. (2006) to those found in the CAM-Oslo, CCSR and LMD-z models. The relative standard deviation of aerosol lifetimes for sulfate, BC and POM for the models used here is $18 \%, 29 \%$, and $18 \%$, respectively, which is similar in magnitude to, but smaller than, the relative standard deviations found in all of the models examined by Textor et al. (2006) (i.e. 20\%, $34 \%$ and 26\%, respectively). For dust aerosols, the models used here included one with a small overall lifetime (1.6 days for the CCSR model) and whereas the lifetime in the LMD-z model is similar to that for other models (3.9 days). The small lifetime for dust in the CCSR model reflects its efficient dry deposition rate (Textor et al., 2006). The effect of this large difference in lifetime, however, may not impact the results reported here, because dust mass tends to reside in the larger particles with small number concentrations, and, therefore, may not significantly affect the global average aerosol indirect effect.

All of the values for cloud forcing reported here are within the range of calculations reported from inverse studies and from models used in applications (i.e. 0 to $-2 \mathrm{Wm}^{-2}$ ) as summarized by Anderson et al. (2003). Nevertheless, since this study only included three models, and since larger diversities in aerosol life cycles are reported in Textor et al. (2006), including diversities in aerosol sources, we think it prudent to more thoroughly examine uncertainties in model simulations of the indirect effect.

These experiments point out the need to improve the representation of liquid water path in the models, especially in light of upcoming new measurements that should provide a more quantitative measure of this field (Stephens et al., 2002). The effect of changing the autoconversion scheme can have important effects especially in models with large liquid water path. There is also clearly a need to improve the parameterization of cloud fraction within the models both in order to improve the calculation of the 2nd indirect effect, as discussed here, as well as to improve the computation of the first indirect effect (Chen and Penner, 2005). Finally, the prediction of aerosol concentrations given a fixed set of sources leads to the largest uncertainties in the indirect 
aerosol effect. Thus, in spite of decreases in the differences in aerosol fields in current models compared to models in the past (Kinne et al., 2006; Penner et al., 2001), there is still a need to improve these basic fields in order to improve the prediction of aerosol indirect effects.

Acknowledgements. We are grateful to P. DeCola and the NASA ACMAP program for encouragement and the support to carry out this study. Partial support from the DOE ARM program is also gratefully acknowledged. A number of people helped to suggest the specific diagnostics used in this study including U. Lohmann, L. Rotstayn, S. Menon, M. Prather, T. Nenes, and P. Adams. We would also like to thank K. Taylor for helping to set up his diagnostic tool CMOR for our use and M. Schultz and S. Kinne for their contribution in posting our model experiment on the AEROCOM website and for encouraging this work. T. Storelvmo also thanks T. Iversen for his help and encouragement with the experiments performed with the CAM-Oslo model.

Edited by: W. Conant

\section{References}

Abdul-Razzak, H. and Ghan, S. J.: A parameterization of aerosol activation, 2. Multiple aerosol types, J. Geophys. Res., 105(D5), 6837-6844, 2000.

Ackerman, A. S., Toon, O. B., Stevens, D. E., Heymsfield, A. J., Ramanathan, V., and Welton, E. J.: Reduction of tropical cloudiness by soot, Science, 245, 1227-1230, 1989.

Ackerman, A. S., Kirkpatrick, M. P., Stevens, D. E., and Toon, O. B.: The impact of humidity above stratiform clouds on indirect aerosol climate forcing, Nature, 432(7020), 1014-1017. 2004.

Anderson, T. L., Charlson, R. J., Schwartz, S. E., Knutti, R., Boucher, O., Rhode, H., and Heintzenberg, J.: Climate forcing by aerosols - A hazy picture, Science, 300, 1103-1104, 2003.

Arakawa, A. and Schubert, W. H.: Interaction of a cumulus cloud ensemble with large-scale environment. 1, J. Atmos. Sci., 31(3), 674-701, 1974.

Berry, E. X.: Cloud droplet growth by collection, J. Atmos. Sci., 24, 688-701, 1967.

Boucher, O. and Lohmann, U.: The sulfate-CCN-cloud albedo effect - a sensitivity study with two general circulation models, Tellus, 47B, 281-200, 1995.

Boucher, O., Le Treut, H., and Baker, M. B.: Precipitation and radiation modeling in a general circulation model: Introduction of cloud microphysical processes, J. Geophys. Res., 100, 1639516414, 1995.

Boucher, O., Pham, M., and Venkataraman, C.: Simulation of the atmospheric sulfur cycle in the Laboratoire de Météorologie Dynamique General Circulation Model. Model description, model evaluation, and global and European budgets, in: Note scientifique de l'IPSL, Vol. 21, edited by: Boulanger, J.-P. and Li, Z.-X., IPSL, Paris, 26pp, 2002.

Bréon, F.-M., Tanré, D., and Generoso, S.: Aerosol effect on cloud droplet size monitored from satellite, Science, 295, 834-838, 2002.

Chen, C. and Cotton, W. R.: The physics of the marine stratocumulus-caped mixed layer, J. Atmos. Sci, 44, 2951-2977, 1987.
Chen, Y. and Penner, J. E.: Uncertainty analysis for estimates of the first indirect effect, Atmos. Chem. Phys., 5, 2935-2948, 2005, http://www.atmos-chem-phys.net/5/2935/2005/.

Dentener, F., Kinne, S., Bond, T., Boucher, O., Cofala, J., Generoso, S., Ginoux, P., Gong, S., Hoelzemann, J. J., Ito, A., Marelli, L., Penner, J., Putaud, J.-P., Textor, C., Schulz, M., van der Werf, G. R., and Wilson, J.: Emissions of primary aerosols and precursor gases in the years 2000 and 1750: Prescribed data sets for AeroCom, Atmos. Chem. Phys. Discuss, 6, 2703-2763, 2006.

Feingold, G., Eberhard, W. L., Veron, D. E., and Previdi, M.: First measurements of the Twomey indirect effect using ground-based remote sensors, Geophys. Res. Lett., 30(6), 1287, doi:10.1029/2002GL016633, 2003.

Feingold, G., Jiang, J. H., and Harrington, J. Y.: On smoke suppression of clouds in Amazonia, Geophys. Res, Lett., 32, L02804, doi:10.1029/2004GL021369, 2005.

Ghan, S. J., Leung, L. R., Easter, R. C., and Abdul-Razzak, H.: Prediction of cloud droplet number in a general circulation model, J. Geophys. Res., 102(D18), 21 777-21 794, 1997.

Ghan, S. J., Easter, R. C., Chapman, E., Abdul-Razzak, H., Zhang, Y., Leung, R., Laulainen, N., Saylor, R., and Zaveri, R.: A physically-based estimate of radiative forcing by anthropogenic sulfate aerosols, J. Geophys. Res., 106, 5279-5293, 2001.

Greenwald, T. J., Stephens, G. L., Vander Haar, T. H., and Jackson, D. L.: A physical retrieval of cloud liquid water over the global oceans using special sensor microwave/imager (SSM/I) observations, J. Geophys. Res., 98, 18 471-18 488, 1993.

Hack, J. J.: Parameterization of moist convection in the NCAR Community Climate Model, CCM2, J. Geophys. Res, 99, 55515568, 1994.

Hansen, J. E., Sato, M., and Ruedy, R.: Radiative forcing and climate response, J. Geophys. Res., 102, 6831-6864, 1997.

Hasumi, H. and Emori, S.: K-1 coupled GCM (MIROC) description, K-1 Technical Report, No. 1, CCSR/NIES/FRCGC, Tokyo, Japan, 2004.

Iversen, T. and Seland, Ø.: A scheme for process-tagged SO4 and BC aerosols in NCAR CCM3. Validation and sensitivity to cloud processes, J. Geophys. Res., 107(D24), 4751, doi:10.1029/2001JD000885, 2002.

Jones, A., Roberts, D. L., and Woodage, M. J.: Indirect sulphate aerosol forcing in a climate model with an interactive sulphur cycle, J. Geophys. Res., 106, 20 293-30 310, 2001.

Kaufman, Y. J., Koren, I., Remer, L. A., Rosenfeld, D., and Rudich, Y.: The effect of smoke, dust, and pollution aerosol on shallow cloud development over the Atlantic Ocean, Proc. National Acad. Sci. USA, 102(32), 11 207-11 212, 2005.

Khairoutdinov, M. and Kogan, Y.: A new cloud physics parameterization in a large eddy simulation model of marine stratocumulus, Mon. Wea. Rev., 128, 229-243, 2000.

Kinne, S., Schulz, M., Textor, C., Guibert, S., Balkanski, Y., Bauer, S. E., Berntsen, T., Berglen, T. F., Boucher, O., Chin, M., Collins, W., Dentener, F., Diehl, T., Easter, R., Feichter, J., Fillmore, D., Ghan, S., Ginoux, P., Gong, S., Grini, A., Hendricks, J., Herzog, M., Horowitz, L., Isaksen, I., Iversen, T., Kirkevåg, A., Kloster, S., Koch, D., Kristjansson, J. E., Krol, M., Lauer, A., Lamarque, J. F., Lesins, G., Liu, X., Lohmann, U., Montanaro, V., Myhre, G., Penner, J. E., Pitari, G., Reddy, S., Seland, O., Stier, P., Takemura, T., and Tie, X.: An AeroCom initial assessment - Optical properties in aerosol component modules of global models, At- 
mos. Chem. Phys., 6, 1815-1834, 2006,

http://www.atmos-chem-phys.net/6/1815/2006/.

Kirkevåg, A. and Iversen, T.: Global direct radiative forcing by process-parameterized aerosol optical properties, J. Geophys. Res., 107(D20), 4433, doi:10.1029/2001JD000886, 2002.

Klein, S. A. and Hartmann, D. L.: The seasonal cycle of low stratiform clouds, J. Clim., 6, 1587-1606, 1993.

Kristjansson, J. E.: Studies of the aerosol indirect effect from sulfate and black carbon aerosols, J. Geophys. Res., 107(D20), 4246, doi:10.1029/2001JD000887, 2002.

Le Treut, H. and Li, Z.-X.: Sensitivity of an atmospheric general circulation model to prescribed SST changes: Feedback processes associated with the simulation of cloud properties, Clim. Dyn., 5, 175-187, 1991.

Li, Z.-X.: Ensemble atmospheric GCM simulation of climate interannual variability from 1979 to 1994 , J. Clim., 12, 986-1001, 1999.

Liou, K.-N. and Ou, S.-C.: The role of cloud microphysical processes in climate: An assessment from a one-dimensional perspective, J. Geophys. Res., 94, 8599-8606, 1989.

Lohmann, U., Feichter, J., Chuang, C. C., and Penner, J. E.: Prediction of the number of cloud droplets in the ECHAM GCM, J. Geophys. Res., 104, 9169-9198, 1999.

Lohmann, U., Feichter, J., Penner, J. E., and Leaitch, R.: Indirect effect of sulfate and carbonaceous aerosols: A mechanistic treatment, J. Geophys. Res., 105, 12 193-12 206, 2000.

Lohmann, U. and Feichter, J.: Global indirect aerosol effects: A review, Atmos. Chem. Phys., 5, 715-737, 2005, http://www.atmos-chem-phys.net/5/715/2005/.

Menon, S., DelGenio, A. D., Koch, D., and Tselioudis, G.: GCM Simulations of the Aerosol Indirect Effect: Sensitivity to Cloud Parameterization and Aerosol Burden, J. Atmos. Sci., 59, 692713, 2002.

Nakajima, T., Higurashi, A., Kawamoto, K., and Penner, J. E.: A possible correlation between satellite-derived cloud and aerosol microphysical parameters, Geophys. Res. Lett., 28, 1171-1174, 2001.

Numaguti, A., Takahashi, M., Nakajima, T., and Sumi, A.: Development of an atmospheric general circulation model, in: Climate System Dynamics and Modeling, edited by: Matsuno, T., Cent. for Clim. Syst. Res., Univ. of Tokyo, Tokyo, 1-27, 1995.

Penner, J. E., Andreae, M., Annegarn, H., Barrie, L., Feichter, J., Hegg, D., Jayaraman, A., Leaitch, R., Murphy, D., Nganga, J., and Pitari, G.: Aerosols, their Direct and Indirect Effects, in: Climate Change 2001: The Scientific Basis, edited by: Houghton, J. T., Ding, Y., Griggs, D. J., Noguer, M., Van der Linden, P. J., Dai, X., Maskell, K., and Johnson, C. A., Report to Intergovernmental Panel on Climate Change from the Scientific Assessment Working Group (WGI), Cambridge University Press, 289-416, 2001.

Penner, J. E., Zhang, S. Y., and Chuang, C. C.: Soot and smoke aerosol may not warm climate, J. Geophys. Res., 108(D21), 4657, doi:10.1029/2003JD003409, 2003.

Penner, J. E., Dong, X., and Chen, Y.: Observational evidence of a change in radiative forcing due to the indirect aerosol effect, Nature, 427, 231-234, 2004.

Platnick, S., King, M. D., Ackerman, S. A., et al.: The MODIS cloud products: Algorithms and examples from Terra, IEEE T. Geosci. Remote Sensing, 41(2), 459-473, 2003.
Quaas, J., Boucher, O., and Bréon, F.-M.: Aerosol indirect effects in POLDER satellite data and the Laboratoire de Météorologie Dynamique-Zoom (LMDZ) general circulation model, J. Geophys. Res., 109, D08205, doi:10.1029/2003JD004317, 2004.

Rasch, P. J. and Kristjánsson, J. E.: A Comparison of the CCM3 Model Climate Using Diagnosed and Predicted Condensate Parameterizations, J. Clim., 11, 1587-1614, 1998.

Reddy, M. S., Boucher, O., Bellouin, N., Schulz, M., Balkanski, Y., Dufresne, J.-L., and Pham, M.: Estimates of multicomponent aerosol optical depth and direct radiative perturbation in the LMDZT General Circulation Model, J. Geophys. Res., 110, D10S16, doi:10.1029/2004JD004757, 2005.

Rotstayn, L. D. and Penner, J. E.: Indirect aerosol forcing, quasiforcing, and climate response, J. Clim., 14, 2960-2975, 2001.

Rotstayn, L. D. and Liu, Y.: A smaller global estimate of the second indirect aerosol effect, Geophys. Res. Lett., 32(5), L05708, doi:10.1029/2004GL021922, 2005.

Slingo, A.: The development and verification of a cloud prediction scheme for the ECMWF model, Quart. J. Roy. Meteorol. Soc., 113, 899-927, 1987.

Storelvmo, T., Kristjansson, J. E., Ghan, S.J., Kirkevåg, A., and Seland, Ø.: Predicting cloud droplet number concentration in CAM-Oslo, J. Geophys. Res., in press, 2006.

Sundqvist, H.: A parameterization scheme for non-convective condensation including prediction of cloud water content, Quart. J. Roy. Meteorol. Soc., 104, 677-690, 1978.

Takemura, T., Nakajima, T., Dubovik, O., Holben, B. N., and Kinne, S.: Single scattering albedo and radiative forcing of various aerosol species with a global three-dimensional model, J. Clim., 15, 333-352, 2002.

Takemura, T., Nozawa, T., Emori, S., Nakajima, T. Y., and Nakajima, T.: Simulation of climate response to aerosol direct and indirect effects with aerosol transport-radiation model, J. Geophys. Res., 110, D02202, doi:10.1029/2004JD005029, 2005.

Textor, C., Schulz, M., Guibert, S., Kinne, S., Balkanski, Y., Bauer, S., Berntsen, T., Berglen, T., Boucher, O., Chin, M., Dentener, F., Diehl, T., Easter, R., Feichter, H., Fillmore, D., Ghan, S., Ginoux, P., Gong, S., Grini, A., Hendricks, J., Horowitz, L., Huang, P., Isaksen, I., Iversen, T., Kloster, S., Koch, D., Kirkevåg, A., Kristjansson, J. E., Krol, M., Lauer, A., Lamarque, J. F., Liu, X., Montanaro, V., Myhre, G., Penner, J., Pitari, G., Reddy, S., Seland, Ø., Stier, P., Takemura, T., and Tie, X.: Analysis and quantification of the diversities of aerosol life cycles within AeroCom, Atmos. Chem. Phys., 6, 1777-1813, 2006,

http://www.atmos-chem-phys.net/6/1777/2006/.

Tiedke, M.: A comprehensive mass-flux scheme for cumulus parameterization in large-scale models, Mon. Wea. Rev., 117, 1779-1800, 1989.

Twomey, S.: Pollution and the planetary albedo, Atmos. Environ., 8, 1251-1256, 1974.

Weng, F. and Grody, N. C.: Retrieval of cloud liquid water using the special sensor microwave imager (SSM/I), J. Geophys. Res., 99, 25 535-25 551, 1994.

Zhang, G. J. and McFarlane, N. A.: Sensitivity of climate simulations to the parameterization of cumulus convection in the Canadian Climate Centre general circulation model, Atmos. Ocean, 33, 407-446, 1995. 